Bryn Mumma, Deborah Diercks, Raphael Twerenbold, André Valcour, André Ziegler, André Schützenmeister, Dusanka Kasapic* and Nam Tran

\title{
Clinical risk assessment of biotin interference with a high-sensitivity cardiac troponin T assay
}

https://doi.org/10.1515/cclm-2019-0962

Received September 13, 2019; accepted July 20, 2020;

published online August 17, 2020

\section{Abstract}

Objectives: Biotin $>20.0 \mathrm{ng} / \mathrm{mL}(81.8 \mathrm{nmol} / \mathrm{L})$ can reduce Elecsys ${ }^{\circledast}$ Troponin T Gen 5 (TnT Gen 5; Roche Diagnostics) assay recovery, potentially leading to false-negative results in patients with suspected acute myocardial infarction (AMI). We aimed to determine the prevalence of elevated biotin and AMI misclassification risk from biotin interference with the TnT Gen 5 assay.

Methods: Biotin was measured using an Elecsys assay in two cohorts: (i) 797 0-h and 646 3-h samples from 850 US emergency department patients with suspected acute coronary syndrome (ACS); (ii) 2023 random samples from a US laboratory network, in which biotin distributions were extrapolated for higher values using pharmacokinetic modeling. Biotin $>20.0 \mathrm{ng} / \mathrm{mL}(81.8 \mathrm{nmol} / \mathrm{L})$ prevalence and biotin 99th percentile values were calculated. AMI misclassification risk due to biotin interference with the TnT Gen 5 assay was modeled using different assay cutoffs and test timepoints.

Results: ACS cohort: 1/797 (0.13\%) 0-h and 1/646 (0.15\%) 3-h samples had biotin $>20.0 \mathrm{ng} / \mathrm{mL}(81.8 \mathrm{nmol} / \mathrm{L})$; 99 th percentile biotin was $2.62 \mathrm{ng} / \mathrm{mL}(10.7 \mathrm{nmol} / \mathrm{L} ; 0-\mathrm{h})$ and

\footnotetext{
*Corresponding author: Dr. Dusanka Kasapic, Roche Diagnostics International Ltd, Forrenstrasse 2, 6343 Rotkreuz, Switzerland, Phone: +41 41798 7242, Fax: +41 417985674

E-mail: dusanka.kasapic@roche.com
}

Bryn Mumma and Nam Tran, UC Davis Medical Center, Sacramento, CA, USA

Deborah Diercks, UT Southwestern Medical Center, Dallas, TX, USA Raphael Twerenbold, Cardiovascular Research Institute Basel (CRIB) and Department of Cardiology, University Hospital Basel, University of Basel, Basel, Switzerland

André Valcour, LabCorp Center for Esoteric Testing, Burlington, NC, USA

André Ziegler, Roche Diagnostics International Ltd, Rotkreuz, Switzerland

André Schützenmeister, Roche Diagnostics GmbH, Penzberg, Germany
$2.38 \mathrm{ng} / \mathrm{mL}$ (9.74 nmol/L; 3-h). Using conservative assumptions, the likelihood of false-negative AMI prediction due to biotin interference was $0.026 \%$ (0-h result; $19 \mathrm{ng} / \mathrm{L}$ TnT Gen 5 assay cutoff). US laboratory cohort: 15/2023 $(0.74 \%)$ samples had biotin $>20.0 \mathrm{ng} / \mathrm{mL}(81.8 \mathrm{nmol} / \mathrm{L})$; 99th percentile biotin was $16.6 \mathrm{ng} / \mathrm{mL}(68.0 \mathrm{nmol} / \mathrm{L})$. Misclassification risk due to biotin interference $(19 \mathrm{ng} / \mathrm{L}$ TnT Gen 5 assay cutoff) was $0.025 \%$ (0-h), $0.0064 \%$ (1-h), $0.00048 \%$ (3-h), and $<0.00001 \%$ (6-h).

Conclusions: Biotin interference has minimal impact on the TnT Gen 5 assay's clinical utility, and the likelihood of false-negative AMI prediction is extremely low.

Keywords: acute myocardial infarction; biotin; false negative; high-sensitivity cardiac troponin $\mathrm{T}$; immunoassay interference; risk of misclassification.

\section{Introduction}

Biotin is a water-soluble vitamin with an adult recommended adequate intake of $30 \mu \mathrm{g}$ per day [1]. Biotinstreptavidin coupling has been used for decades by manufacturers of in-vitro diagnostic (IVD) devices to immobilize biotinylated proteins [2,3]; however, these immunoassays are susceptible to interference from excessive blood biotin concentrations.

The biotin-streptavidin-based Elecsys ${ }^{\circledast}$ Troponin $\mathrm{T}$ Gen 5 (TnT Gen 5; marketed outside the United States [US] as Elecsys Troponin T-high sensitive; Roche Diagnostics International Ltd, Rotkreuz, Switzerland) assay provides a high negative predictive value (NPV; $\geq 99 \%$ ) for ruling out acute myocardial infarction (AMI) [4-8]. Biotin concentrations $>20.0 \mathrm{ng} / \mathrm{mL}(81.8 \mathrm{nmol} / \mathrm{L})$ can reduce $\mathrm{TnT}$ Gen 5 assay recovery [9], which may lead to lower reported cardiac troponin $\mathrm{T}$ (cTnT) concentrations, and thus false-negative AMI prediction. However, the incidence of biotin interference and its clinical implications in the TnT Gen 5 assay intended-use population is unknown.

Until recently, immunoassay interference from biotin was considered extremely rare, as interference thresholds are considerably higher than blood 
concentrations associated with the recommended dietary biotin intake. However, very high biotin doses (up to $300 \mathrm{mg}$ daily) have been used in clinical trials for treating multiple sclerosis (MS) and high-dose biotin supplements (up to $10 \mathrm{mg}$ in single-ingredient preparations) have been marketed for cosmetic purposes, which may increase the risk of biotin interference [10-16]. In 2011-2012, 29\% of US adults reported using biotincontaining supplements [17]. In a 2017 US prevalence study, biotin use was reported by $7.7 \%$ of outpatients [18]. Biotin doses ranged from $<1$ to $50 \mathrm{mg} ; 47.0 \%$ of respondents reported taking $\leq 10 \mathrm{mg}$, and $44.9 \%$ did not know the dose they were taking or did not respond [18]. In the same study, $7.4 \%$ of emergency department patients had plasma biotin concentrations $\geq 10 \mathrm{ng} / \mathrm{mL}$ (40.9 nmol/L) [18]. Nielsen US retail sales data for July 2014 to June 2017 showed a slight increase in biotin sales. However, the data also suggest most consumers are taking biotin doses that pose a low interference risk, with the steadiest growth in $\leq 2.5 \mathrm{mg}$ doses; sales of $5 \mathrm{mg}$ biotin declined [19].

We aimed to determine the prevalence of elevated biotin concentrations and the associated patient misclassification risk due to biotin interference with the TnT Gen 5 assay in the US intended-use population. We also performed a second risk analysis using extrapolated biotin prevalence data based on random samples from a US laboratory network representative of the general US population. Patient misclassification risk was evaluated according to International Organization for Standardization (ISO) 14971 and Clinical and Laboratory Standards Institute (CLSI) guidelines [20, 21].

\section{Materials and methods}

\section{TnT Gen 5 test principle}

The Elecsys Troponin T Gen 5 assay is an electrochemiluminescence sandwich immunoassay, comprising a biotinylated monoclonal anti-cTnT-specific antibody and a monoclonal anti-cTnT-specific antibody labeled with ruthenium [9]. These antibodies react to form a sandwich complex with cTnT, which is then bound to the solid phase via biotin-streptavidin interaction [9]. The TnT Gen 5 assay has previously demonstrated good analytical performance and met precision requirements [9]: limit of detection $5 \mathrm{ng} / \mathrm{L}$ (cobas e 411 analyzer) and $3 \mathrm{ng} / \mathrm{L}$ (cobas e 601 analyzer); measuring range $6-10,000 \mathrm{ng} / \mathrm{L}$ (both analyzers); repeatability and intermediate precision coefficients of variation (CVs) $0.7-5.6 \%$ and $1.4-10.3 \%$, respectively (cobas e 411 analyzer; mean cTnT concentrations $7.3-9341 \mathrm{ng} / \mathrm{L}$ in lithium-heparin plasma samples), and $0.7-3.0 \%$ and $1.5-6.4 \%$, respectively (cobas e 601 analyzer; mean cTnT concentrations 7.4-9,455 ng/L in lithium-heparin plasma samples); 10\% CV (total imprecision) $11 \mathrm{ng} / \mathrm{L} ; \mathrm{CV}$ at 99th percentile upper reference limit 3.92 (cobas e 411 analyzer) and 3.18 (cobas e 601 analyzer). TnT Gen 5 assay recovery can fall to $90 \%$ at biotin concentrations of $20.0 \mathrm{ng} / \mathrm{mL}(81.8 \mathrm{nmol} /$ $\mathrm{L}$ ); higher biotin concentrations can reduce assay recovery further (Figure 1). No interference has been observed with biotin $\leq 20.0 \mathrm{ng} / \mathrm{mL}$ $(81.8 \mathrm{nmol} / \mathrm{L})[9]$.

\section{Study design}

The prevalence of elevated biotin and the clinical risk of biotin interference with the TnT Gen 5 assay was evaluated using two distinct study cohorts and risk assessment models (Figure 2). In each model, the impact of biotin interference on the NPV of the TnT Gen 5 assay and the likelihood of false-negative AMI prediction was estimated, based on the prevalence of biotin $>20.0 \mathrm{ng} / \mathrm{mL}(81.8 \mathrm{nmol} / \mathrm{L})$ in each cohort, the distribution of cTnT concentrations (as specified in each model below), and the biotin interference curve for the TnT Gen 5 assay.

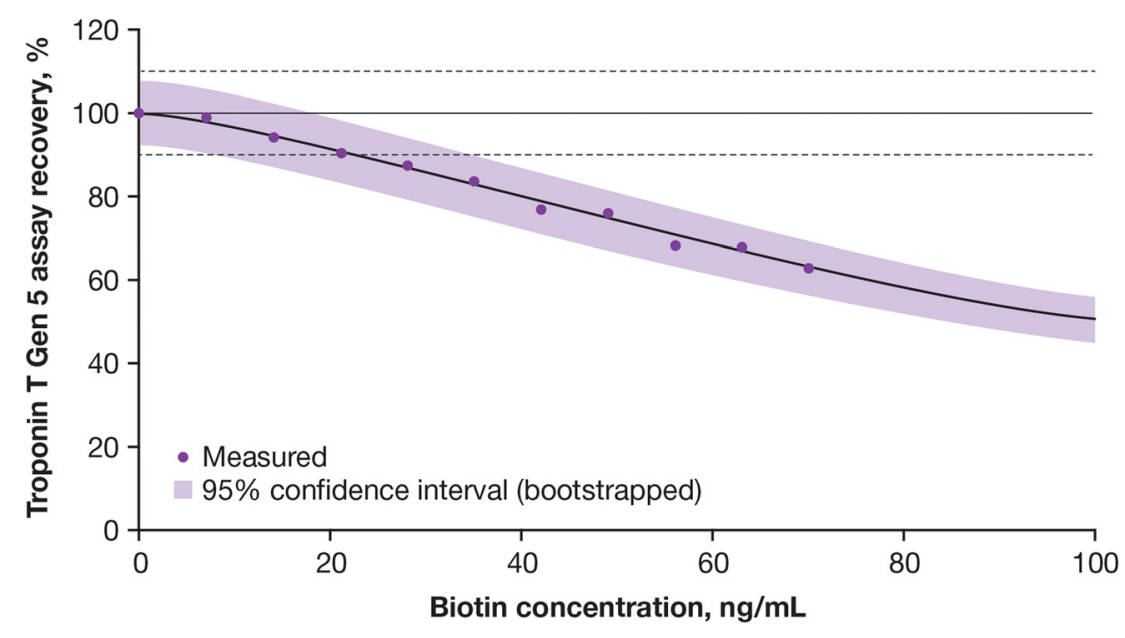

Figure 1: Impact of biotin interference on Elecsys Troponin T Gen 5 assay recovery. Troponin recovery was measured on the cobas e 411 analyzer using samples with a cardiac troponin T concentration of $16.2 \mathrm{ng} /$ L, which were spiked with measured concentrations of biotin. A non-linear doseresponse model was fitted to the measured data and was used to predict recovery values in samples with up to $100 \mathrm{ng} / \mathrm{mL}(409 \mathrm{nmol} /$ L) biotin. 


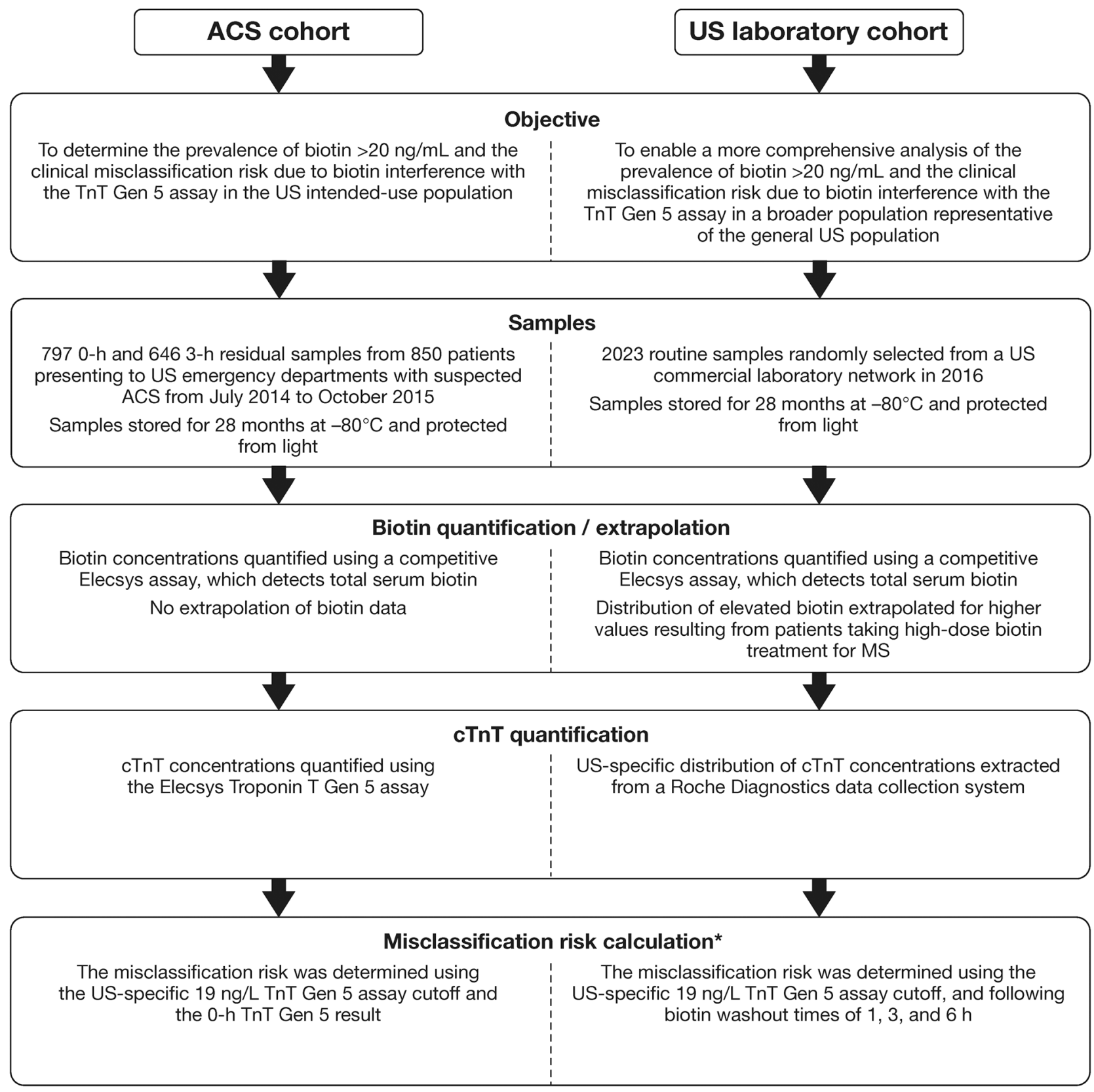

Figure 2: Overview of the two study cohorts/risk assessment models used to determine the prevalence of elevated biotin and the clinical risk of biotin interference with the TnT Gen 5 assay.

*A risk calculation model was built based on biotin prevalence data, distribution of cTnT concentrations, and the biotin interference curve for the TnT Gen 5 assay. A misclassification was defined as a cTnT above the cutoff, which could be reported as below the cutoff due to biotin interference, and thus lead to a false-negative result. ACS, acute coronary syndrome; cTnT, cardiac troponin T; TnT Gen 5, Troponin T Gen 5; US, United States.

\section{Model 1: risk calculation based on biotin prevalence data from a cohort of patients with suspected acute coronary syndrome (ACS cohort)}

The ACS cohort comprised 850 patients presenting to 16 US emergency departments with suspected ACS from July 2014 to October 2015 and aimed to represent the TnT Gen 5 assay intended-use population in the
US; this cohort has been previously described [8]. The original study received ethics approval from all relevant institutional review boards, and was conducted in accordance with the principles of the Declaration of Helsinki and the International Conference on Harmonization guidelines for Good Clinical Practice. All patients provided informed consent. In the original study, 1679 patients (48\% female; median age 55 years [interquartile range: 47-64]) had a TnT Gen 5 assay result available at one or more time point; all patients had an available result 
on the cobas e 411 analyzer and 1675 patients had an available result on the cobas e 601 analyzer. Of these, 850 patients who had sufficient residual 0-h (admission) and/or 3-h sample volume to measure biotin, and consented to future use of their samples, were included in the present analyses. Samples were stored for 28 months at $-80{ }^{\circ} \mathrm{C}$ and protected from light prior to biotin analysis. Biotin has been shown to be stable following frozen storage and freeze/thaw cycles [22] and has an effective half-life of $15 \mathrm{~h}$ [23]. Biotin was quantified using a competitive Elecsys research assay on the cobas e 411 analyzer (Roche Diagnostics International Ltd, Rotkreuz, Switzerland): limit of detection $4.88 \mathrm{ng} / \mathrm{L}$ (cobas e 411 analyzer) and $2.05 \mathrm{ng} / \mathrm{L}$ (cobas e 601 analyzer); measuring range 3-10,000 ng/L (both analyzers); intermediate precision CV $2.81 \mathrm{ng} / \mathrm{L}$ (cobas e 411 analyzer) and $2.20 \mathrm{ng} / \mathrm{L}$ (cobas e 601 analyzer); 10\% CV (total imprecision) $5.03 \mathrm{ng} / \mathrm{L}$ (cobas e 411 analyzer) and $4.49 \mathrm{ng} / \mathrm{L}$ (cobas e 601 analyzer); CV at 99th percentile upper reference limit $<10 \%$ (both analyzers) [24]. This assay detects total serum biotin (free biotin, bound biotin/biocytin, and biotin metabolites) with a lower limit of detection of $0.1 \mathrm{ng} / \mathrm{mL}$ (0.41 nmol/L), and has been validated against a liquid chromatography-tandem mass spectrometry method at biotin concentrations of 40.0 to $300 \mathrm{ng} / \mathrm{mL}$ (164 to $1228 \mathrm{nmol} / \mathrm{L}$ ) (Supplemental Figure 1). A comparison of these methods for biotin concentrations $<40.0 \mathrm{ng} / \mathrm{mL}(163.7 \mathrm{nmol} / \mathrm{L})$ was not assessed.

A risk calculation model was built based on the measured prevalence of biotin $>20.0 \mathrm{ng} / \mathrm{mL}(81.8 \mathrm{nmol} / \mathrm{L})$ and distribution of $\mathrm{cTnT}$ concentrations in the ACS cohort, and the biotin interference curve for the TnT Gen 5 assay. The prevalence of cTnT concentrations around the 99th percentile upper reference limit for the TnT Gen 5 assay was evaluated, respecting the diagnostic criteria of the Third Universal Definition of Myocardial Infarction (the adjudication process for diagnosing AMI was performed before the publication of the updated fourth definition). This requires detection of a rise and/or fall in cardiac troponin (cTn) values, with at least one value above the 99th percentile upper reference limit, alongside clinical evidence of AMI [25]. The misclassification risk was determined using the US-specific $19 \mathrm{ng} / \mathrm{L}$ TnT Gen 5 assay cutoff. A misclassification was defined as a cTnT above the cutoff, which could be reported as below the cutoff due to biotin interference, and thus lead to a false-negative result.

The following assumptions were used: (i) the highest anticipated biotin concentration was derived by multiplying the highest observed concentration in the ACS cohort by three, per CLSI EP07 guidelines [26]; (ii) the prevalence of $0-\mathrm{h}$ biotin $>20 \mathrm{ng} / \mathrm{mL}(81.8 \mathrm{nmol} / \mathrm{L})$ and $\leq 100 \mathrm{ng} / \mathrm{mL}$ ( $409 \mathrm{nmol} / \mathrm{L})$ was derived from the upper confidence limit of the observed prevalence in the ACS cohort; (iii) the maximal reduction in TnT Gen 5 assay recovery at a biotin concentration of $100 \mathrm{ng} / \mathrm{mL}$ (409 nmol/L) was 42\%; and (iv) the AMI prevalence was extrapolated to $15 \%$, a more conservative, yet realistic, estimate based on the measured prevalence of $10.3 \%$ in the ACS cohort [8].

\section{Model 2: risk calculation based on extrapolated biotin prevalence data in random samples from a US laboratory network (US laboratory cohort)}

To enable a more comprehensive assessment of the risk of biotin interference with the TnT Gen 5 assay, a second study cohort was utilized to provide biotin prevalence data from a broader population than the ACS cohort. The US laboratory cohort was intended to reflect the general US population and comprised 2023 routine blood samples randomly selected from a US commercial laboratory network in 2016.
Samples were stored for 2 weeks at $-20^{\circ} \mathrm{C}$ and protected from light prior to biotin analysis. Biotin was quantified using a competitive Elecsys research assay on the cobas e 411 analyzer (Roche Diagnostics International Ltd, Rotkreuz, Switzerland). For a more conservative approach and to evaluate a worst-case scenario, the measured prevalence of elevated biotin $>20 \mathrm{ng} / \mathrm{mL}$ in the US laboratory cohort was extrapolated to higher biotin values, such as patients taking very high biotin doses for MS. This extrapolation was based on previous pharmacokinetic studies and a biotin prevalence study of US emergency department patients [10, 18, 23, 27].

A risk calculation model was built based on the extrapolated prevalence of biotin $>20.0 \mathrm{ng} / \mathrm{mL}(81.8 \mathrm{nmol} / \mathrm{L})$, a US-specific distribution of cTnT concentrations extracted from a global Roche Diagnostics data collection system of participating customers, and the biotin interference curve for the TnT Gen 5 assay. The misclassification risk was determined using TnT Gen 5 assay cutoffs of 14, 19, and $22 \mathrm{ng} /$ $\mathrm{L}$ (to cover non-US combined, US-combined, and US sex-specific cutoffs), and following biotin washout times of 1,3 , and $6 \mathrm{~h}$ by applying the pharmacokinetic data described previously [23]. These washout times were chosen to reflect commonly used time points for serial TnT Gen 5 testing. We also evaluated the misclassification risk of biotin interference if using a TnT Gen 5 assay cutoff of $6 \mathrm{ng} / \mathrm{L}$ (i.e. the assay's limit of quantitation) for 0 -h result. Specifically, we assessed the risk of biotin interference causing a true TnT Gen 5 result of $\geq 6 \mathrm{ng} / \mathrm{L}$ to be recorded as $<6 \mathrm{ng} / \mathrm{L}$. The rationale behind this analysis was that a cutoff of $6 \mathrm{ng} / \mathrm{L}$ for 0 -h TnT Gen 5 result is commonly used in US emergency departments to decide whether a patient should be ruled out for AMI ( $<6 \mathrm{ng} / \mathrm{L}$ ) or undergo serial cTn testing ( $\geq 6 \mathrm{ng} / \mathrm{L})$, although it should be emphasized that this is an off-label use of the TnT Gen 5 assay.

Further details on this second risk calculation model are provided in the online Supplemental Material.

\section{Risk assessment per ISO 14971 guidelines}

A risk assessment was performed to evaluate the probability and clinical consequences of misclassification due to biotin interference with the TnT Gen 5 assay, according to ISO 14971 guidelines [20].

\section{Results}

\section{Model 1: risk calculation based on biotin prevalence data from the ACS cohort}

\section{Prevalence of elevated biotin}

Biotin was undetectable $(<0.1 \mathrm{ng} / \mathrm{mL} ;<0.41 \mathrm{nmol} / \mathrm{L})$ in $471 /$ 797 (59\%) 0-h samples and 399/646 (62\%) 3-h samples (Supplemental Figure 5). The 99th percentile biotin concentrations were $2.62 \mathrm{ng} / \mathrm{mL}(10.7 \mathrm{nmol} / \mathrm{L})$ at $0-\mathrm{h}$ and $2.38 \mathrm{ng} / \mathrm{mL}(9.74 \mathrm{nmol} / \mathrm{L})$ at $3-\mathrm{h}$, seven times lower than the biotin interference threshold for the TnT Gen 5 assay of $20.0 \mathrm{ng} / \mathrm{mL}(81.8 \mathrm{nmol} / \mathrm{L})$. Biotin $>20.0 \mathrm{ng} / \mathrm{mL}(81.8 \mathrm{nmol} /$ L), which might influence TnT Gen 5 results by $>10 \%$, was identified in one sample at each time point (0-h, $30.23 \mathrm{ng} /$ 
$\mathrm{mL} ; 124 \mathrm{nmol} / \mathrm{L})$ and (3-h, $24.48 \mathrm{ng} / \mathrm{mL} ; 100 \mathrm{nmol} / \mathrm{L})$; the corresponding prevalence of biotin $>20.0 \mathrm{ng} / \mathrm{mL}$ ( $81.8 \mathrm{nmol} / \mathrm{L})$ was $0.13 \%$ (0-h; $95 \%$ confidence interval [CI] 0-0.70) and 0.15\% (3-h; 95\% CI 0-0.86). Both samples were from a 60 -year-old female patient who was correctly not diagnosed with AMI; 0-h TnT Gen 5 results for this patient were $5.70 \mathrm{ng} / \mathrm{L}$ (cobas e 411) and $5.51 \mathrm{ng} / \mathrm{L}$ (cobas e 601); 3-h TnT Gen 5 results were $5.15 \mathrm{ng} / \mathrm{L}$ (cobas e 411) and $5.74 \mathrm{ng} / \mathrm{L}$ (cobas e 601).

Among the 850 patients included in this analysis, 257 (30\%) had a single biotin measurement available, 325 (38\%) had undetectable biotin $(<0.1 \mathrm{ng} / \mathrm{mL} ; 0.41 \mathrm{nmol} / \mathrm{L})$ in both samples, and $73(9 \%)$ had undetectable biotin in one of the two samples. Thus, 195 (23\%) patients had detectable biotin in both samples available to calculate biotin kinetics in the ACS cohort. The median change in biotin between 0 -h and 3-h serial samples was $-0.015 \mathrm{ng} / \mathrm{mL}(0.061 \mathrm{nmol} / \mathrm{L})$ (interquartile range: -0.050 to $0.002 \mathrm{ng} / \mathrm{mL}$ ).

\section{Risk calculation}

The following assumptions were used: (i) the highest biotin concentration was $100.0 \mathrm{ng} / \mathrm{mL}$ (409 nmol/L) which is approximately three times the highest observed biotin concentration of $30.23 \mathrm{ng} / \mathrm{mL}(124 \mathrm{nmol} / \mathrm{L})$ in the intended use population; (ii) the prevalence of 0 -h biotin $>20.0 \mathrm{ng} / \mathrm{mL}$ $(81.8 \mathrm{nmol} / \mathrm{L})$ and $\leq 100 \mathrm{ng} / \mathrm{mL}(409 \mathrm{nmol} / \mathrm{L})$ was $0.7 \%$ (upper confidence limit of observed prevalence); (iii) the maximal reduction in TnT Gen 5 assay recovery at a biotin concentration of $100 \mathrm{ng} / \mathrm{mL}(409 \mathrm{nmol} / \mathrm{L}$ ) was 42\%; and (iv) the AMI prevalence was $15 \%$. Based on these assumptions, only a 0 -h TnT Gen 5 result between 19 and 45.24 ng/L could lead to false-negative AMI classification, using the US overall $19 \mathrm{ng} / \mathrm{L}$ cutoff. As $25 \%$ of patients diagnosed with AMI in the ACS cohort had a 0-h TnT Gen 5 result within this range, the likelihood of false-negative results due to biotin interference was estimated as $0.026 \%$ (Figure 3).

\section{Model 2: risk calculation based on extrapolated biotin prevalence data from the US laboratory cohort}

\section{Prevalence of elevated biotin}

Biotin $>20.0 \mathrm{ng} / \mathrm{mL}(81.8 \mathrm{nmol} / \mathrm{L})$ was identified in $15 / 2023$ $(0.74 \%)$ samples; the highest measured biotin concentration

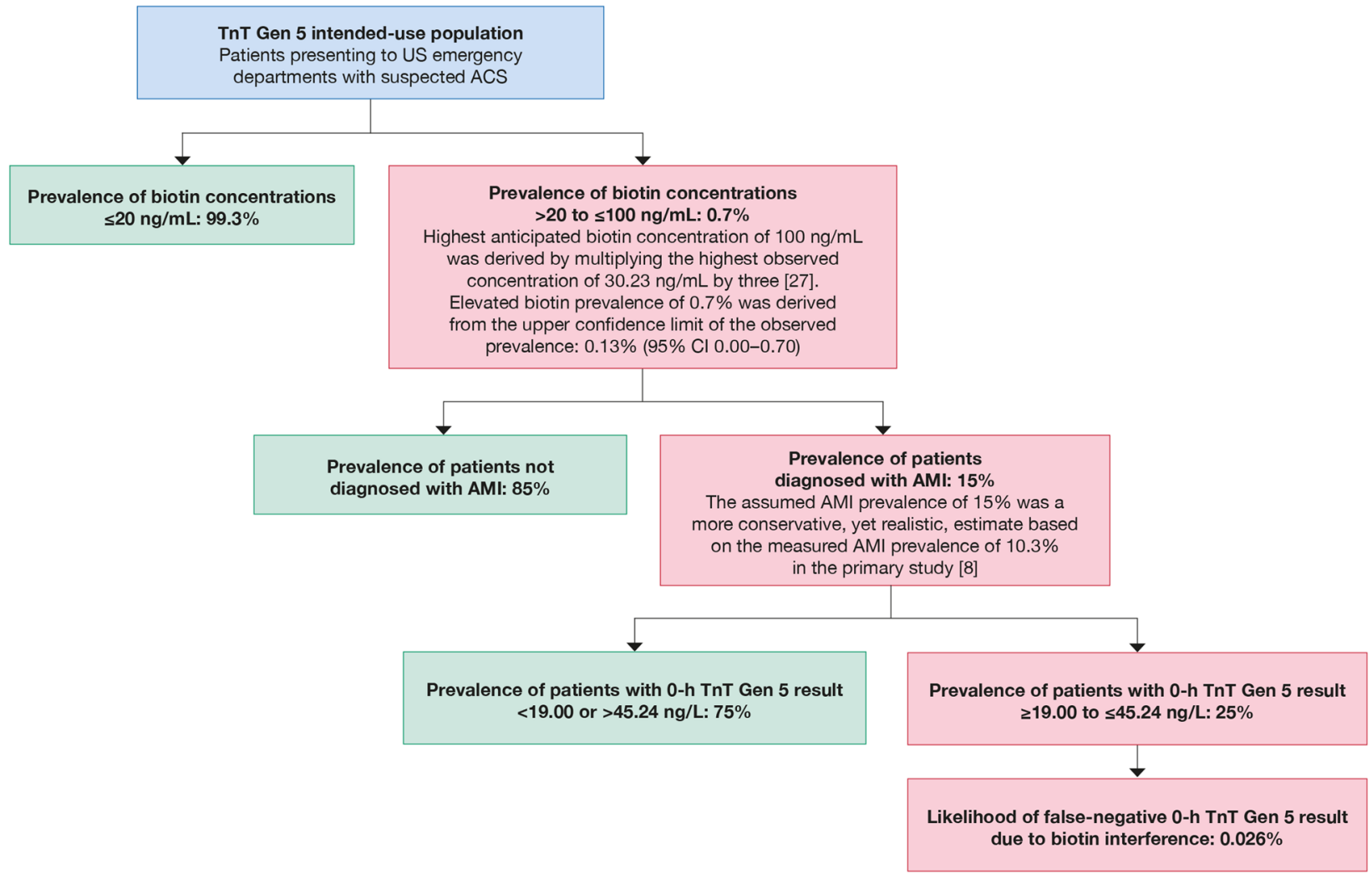

Figure 3: Estimating the probability of false-negative AMI prediction due to biotin interference with the TnT Gen 5 assay (based on 0-h result). ACS, acute coronary syndrome; AMI, acute myocardial infarction; Cl, confidence interval; TnT Gen 5, Troponin T Gen 5; US, United States. 
was $92.7 \mathrm{ng} / \mathrm{mL}$ (379 nmol/L). The measured biotin prevalence was extrapolated anticipating patients receiving highdose biotin treatment for MS. This resulted in extrapolated biotin concentrations of $100-600 \mathrm{ng} / \mathrm{mL}(409-2456 \mathrm{nmol} / \mathrm{L})$ (Figure 4), which is higher than has been previously observed in the intended-use population for cTn testing [18].

\section{Risk calculation}

Based on extrapolated biotin data, predicted elimination of biotin in blood, and US-specific cTnT distribution data from the Roche data collection system, the misclassification risk due to biotin interference with the TnT Gen 5 assay, using the US-specific $19 \mathrm{ng} / \mathrm{L}$ cutoff, was $0.025 \%$ (0-h), $0.0064 \%$ (1-h), $0.00048 \%$ (3-h), and $<0.00001 \%$ (6-h). Using different TnT Gen 5 assay cutoffs in the modeling produced the following misclassification risk estimates: $14 \mathrm{ng} / \mathrm{L}$ (non-US combined cutoff/US female-specific cutoff), $0.026 \%$ (0-h) and $0.0067 \%$ (1-h); $22 \mathrm{ng} / \mathrm{L}$ (US male-specific cutoff), $0.029 \%$ (0-h) and $0.0075 \%$ (1-h). Comparable misclassification estimates were obtained when applying a global distribution of cTnT data to the modeling, rather than a US-specific distribution alone: 0-h $19 \mathrm{ng} / \mathrm{L}$ cutoff, $0.025 \%$; 0-h $14 \mathrm{ng} / \mathrm{L}$ cutoff, $0.027 \%$. This risk calculation model was also applied to the ACS cohort biotin prevalence data, which showed a misclassification risk of $<0.00001 \%(0-\mathrm{h})$. The risk of biotin interference causing a true $\mathrm{TnT}$ Gen 5 result of $\geq 6 \mathrm{ng} / \mathrm{L}$ to be recorded as $<6 \mathrm{ng} / \mathrm{L}$ was $0.063 \%(0-h)$.

\section{Risk assessment per ISO 14971 guidelines}

The severity of biotin interference with the TnT Gen 5 assay can be described as high due to the risk associated with AMI misclassification. However, the probability of misclassification occurring was judged to be low $(0.026 \%)$.

\section{Discussion}

Biotin interference with biotin-streptavidin-based assays is of increasing interest due to biotin supplementation marketed for cosmetic use and trials of high-dose biotin for treating MS [10-16]. CLSI EP07 guidelines recommend that potential assay interferents are tested at the highest concentration expected in the intended-use population [26]. However, manufacturer-reported assay interference thresholds for biotin are based on historic reference ranges $(<1.0 \mathrm{ng} / \mathrm{mL} ; 4.09 \mathrm{nmol} / \mathrm{L})[28,29]$, and attempts to address biotin interference are limited by the poorly documented pharmacokinetic profile for biotin [23]. We explored the impact of biotin interference on the biotin-streptavidinbased TnT Gen 5 assay. At least one cTn measurement above the 99th percentile upper reference limit is necessary, although not sufficient alone, for AMI diagnosis [25]. As such, false-negative TnT Gen 5 results due to biotin interference have potential clinical implications.

The prevalence of elevated biotin in our study (ACS cohort, $0.13-0.15 \%$; US laboratory cohort, $0.74 \%$ ) is consistent with that reported in routine cTnT samples from an Australian population (0.2\%) [30], but is lower than observed in previous research of patients presenting to a US emergency department (1.7\%) [31]. Differences may be due to geographic differences in biotin consumption and a lack of standardization for all current, biotin assays. For instance, in an Australian study [30], biotin was measured by liquid chromatography-mass spectrometry (LC-MS)/MS
Starting point: biotin prevalence in 2023 unselected samples from a US commercial laboratory network
Biotin prevalence adjusted at higher concentrations according to literature and samples from patients with multiple sclerosis receiving high-dose biotin treatment
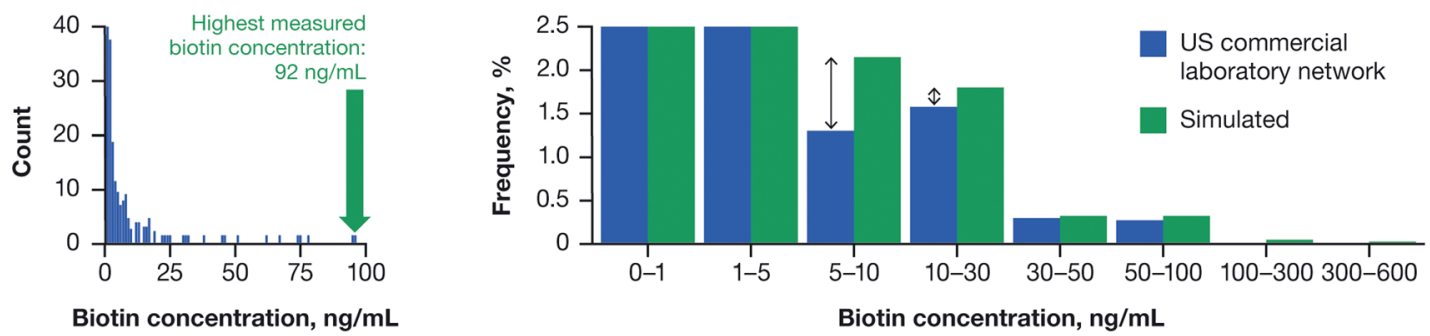

Figure 4: Measured and extrapolated biotin prevalence data based on random samples from a US commercial laboratory network and scientific literature.

The simulated biotin prevalence assumed a higher biotin prevalence, and thus higher degree of risk, than observed in the laboratory samples. US, United States. 
(Shimadzu), whereas, in our study, biotin concentration was analyzed by LC-MS and an in-house Elecsys research assay on a cobas e 411 analyzer [23]. The differences in methods and inter-laboratory instrument calibration can result in discrepancies and there is currently no standard approach. By defining biotin concentration and interference with the same assay, our methods are comparable and valid.

We demonstrated that the likelihood of false-negative AMI prediction due to biotin interference with the TnT Gen 5 assay is very low in the intended-use population $(0.026 \%$, based on 0-h TnT Gen 5 result). This is lower than reported in a previous study, which estimated that up to $0.8 \%$ of US emergency department patients would be at risk of a clinically significant cTnT decrease (defined as any change in cTnT of $4 \mathrm{ng} / \mathrm{L}$ or 10\%) caused by biotin interference [31]. Our definition of a clinically significant cTnT decrease is more stringent: 10\% decrease at the US overall $19 \mathrm{ng} / \mathrm{L} \mathrm{TnT}$ Gen 5 assay cutoff (approximately $2 \mathrm{ng} / \mathrm{L}$ ). Importantly, our results show that the misclassification risk with the TnT Gen 5 assay is not determined by the assay biotin interference threshold alone. The prevalence of elevated biotin in the intended-use population, the shape of the assayspecific biotin recovery curve, and the test analyte distribution with respect to the assay cutoff are also key factors.

We developed a second risk model, which included more recent samples from a US commercial laboratory network and aimed to address a worst-case scenario by anticipating very high biotin concentrations in patients with MS taking high-dose biotin treatments/supplements. The misclassification rate due to biotin interference in this model, based on a US-specific distribution of cTnT data, the US-specific TnT Gen 5 assay cutoff of $19 \mathrm{ng} / \mathrm{L}$, and a strict and conservative risk assessment, remained extremely low: $0.025 \%(0-h)$ to $<0.00001 \%(6-h)$. Similar misclassification risk estimates were obtained when using non-US and US sex-specific TnT Gen 5 assay cutoffs (14 and $22 \mathrm{ng} / \mathrm{L})$.

The present misclassification rates due to biotin interference are considerably lower than those caused by other factors related to the clinical performance of cTn assays. For the TnT Gen 5 assay, the misclassification rate would be $0.7 \%$, based on an NPV of $99.3 \%$ at $3 \mathrm{~h}$ [8], or $0.6 \%$, based on an NPV of $99.4 \%$ [32]. For contemporary cTn assays, a meta-analysis reported an NPV of 98.2\%, which equates to a misclassification rate of $1.8 \%$, and reflects the current standard of care for cTn assays and thus user expectations [33]. The misclassification rate of a highsensitivity cardiac troponin I (cTnI) assay would be $1.5 \%$, based on an NPV of 98.5\% [32]. A typical assay imprecision of $3-6 \%$ would translate into a misclassification risk of $0.30-0.64 \%$; coefficients of variation for intermediate precision with the TnT Gen 5 assay range from 1.4 to $10.3 \%$ (cobas e 411 analyzer) and from 1.5 to $6.4 \%$ (cobas e 601 analyzer) [9].

The American Heart Association/American College of Cardiology guidelines recommend serial cTn testing, with an additional draw after 3-6 h [34]. Biotin concentrations should decrease during this period, thus reducing the risk of interference and a false-negative result. However, the introduction of high-sensitivity cTn assays has prompted an increasing trend for accelerated diagnostic protocols and faster clinical decision-making than the traditional 3-6-h algorithms. The European Society of Cardiology guidelines include a 0/1-h algorithm for high-sensitivity cTn assays [35], and some AMI diagnostic algorithms incorporate risk scores before cTn testing or with the initial cTn result. Risk scores and clinical judgment may provide an additional safety layer, as high-risk patients should be investigated further, despite a non-elevated cTn.

Although our findings show that the misclassification risk from biotin interference with the TnT Gen 5 assay is low, special attention should be paid to patients taking high-dose biotin and those with inherited biotin metabolism disorders (e.g., biotinidase and holocarboxylase synthetase deficiencies). Clinicians should ask patients about recent biotin consumption, perform serial cTn measurements, and be aware that $\mathrm{TnT}$ Gen 5 results may be falsely depressed. TnT Gen 5 assay measurements should be repeated in patients with clinical signs of AMI, but a negative initial TnT Gen 5 result, taking into account expected biotin clearance times. In contrast to high-dose biotin, biotin doses $<5 \mathrm{mg}$, which are commonly found in multivitamin and biotin supplements, are unlikely to lead to blood biotin concentrations that pose an interference risk with the TnT Gen 5 assay [23]. However, patients with renal impairment may have altered biotin kinetics and receive supplements of water soluble vitamins especially under dialysis [36]. The interpretation of cTn in patients with renal failure is complicated by concomitant chronic structural heart disease rather than acute injury [37], and cTn is often persistently elevated and affected by hemodialysis timing and membrane used in this population. Further research is required to examine the effects of biotin in patients with chronic kidney disease.

All immunoassays can be affected by interferences [38]; collectively, these likely contribute to the fact that NPVs of cTn assays using the 99th percentile upper reference limit during serial sampling are 95-99\% [33]. Our findings suggest that biotin interference is far less 
prevalent than other interferences that can affect cTn assays $[39,40]$. In spite of the low risk, the TnT assay has recently been updated (Gen 5 reformulated) to a biotin interference threshold of $1,200 \mathrm{ng} / \mathrm{mL}(4.91 \mathrm{umol} / \mathrm{L})$.

Strengths of the present analyses are that the biotin interference risk with the TnT Gen 5 assay was assessed using a conservative approach for estimating the probability of false-negative AMI prediction, and that biotin prevalence data were determined from a range of populations. The risk of biotin interference is dependent on the prevalence of elevated biotin in the target population, the assay's biotin interference tolerance, and the test analyte concentration. Therefore, our findings are specific to the TnT Gen 5 assay and the US population, and are not generalizable to other assays or populations. Biotin interference thresholds for cTn assays range from 2.5 to $10,000 \mathrm{ng} / \mathrm{mL}(10.2 \mathrm{nmol} / \mathrm{L}$ to $40.9 \mathrm{umol} / \mathrm{L})$ [41], and the threshold for the TnT Gen 5 assay of $20.0 \mathrm{ng} / \mathrm{mL}(81.8 \mathrm{nmol} /$ $\mathrm{L}$ ) is on the lower end of this range. It should also be noted that cTnT measured using high-sensitivity assays may differ depending on the assay equipment used for analysis. Although samples were stored frozen for prolonged periods and were not freshly analyzed, biotin has been shown to be stable following frozen storage and freeze/thaw cycles [22]. A limitation of the study was that the samples used were not specifically collected for the purpose of measuring biotin levels. Prior studies have shown that biotin is stable under such conditions [42]. Our data reflect biotin distribution in the intended use population for troponin testing, but might differ from broader or more selected populations. In the ACS cohort, biotin was undetectable in the majority of samples. This may suggest that the ACS cohort had lower biotin concentrations than might be expected in the general population; however, biotin reference intervals vary and there is no standardization of biotin assays. Another limitation of the study is that the biotin assay was validated against a liquid chromatography-tandem mass spectrometry method for biotin concentrations of $40.0-300 \mathrm{ng} / \mathrm{mL}(164-1228 \mathrm{nmol} /$ $\mathrm{L})$, but not below. While values $<40.0 \mathrm{ng} / \mathrm{mL}(164 \mathrm{nmol} / \mathrm{L})$ may therefore be insufficiently checked between methods, the most important factor was to check for reliability of comparability of higher concentrations, which are critical in terms of interference. The critical concentration range of biotin has been recently confirmed in external studies [43, 44].

Patients with renal insufficiency, pregnancy, and recent hospitalization were excluded from the original ACS cohort; therefore, our findings may not be generalizable to these groups. This is in keeping with standard algorithms for diagnosing AMI, which are not applicable to patients with renal dysfunction [25]. Our worst-case scenario modeling was based on assumptions rather than measured data, and we do not know the proportion of patients with MS in the study cohorts who may have been taking highdose biotin. The ACS cohort data suggest that no patients with MS taking high-dose biotin treatment were included in this cohort. In the risk model derived from the US laboratory cohort, the measured biotin prevalence data were extrapolated to anticipate very high biotin concentrations resulting from high-dose biotin treatment for MS.

In conclusion, biotin interference has a minimal impact on the clinical utility of the Elecsys Troponin T Gen 5 assay, and the likelihood of false-negative AMI prediction in the intended-use population is low. However, further research is required to understand completely biotin interference as a concern. Medical and laboratory staff should be aware of the potential risk for biotin interference, and pay particular attention to results from high-risk groups, such as patients with MS. It is important that clinicians evaluate results in the context of the wider clinical picture, ask patients about recent biotin/multivitamin supplement use, and perform serial cTn testing.

Acknowledgments: This study was funded by Roche Diagnostics International Ltd, Rotkreuz, Switzerland. Thirdparty medical writing assistance, under the direction of the authors, was provided by Thomas Burton, BMBS (GardinerCaldwell Communications, Macclesfield, UK) and was funded by Roche Diagnostics International Ltd. COBAS, COBAS E and ELECSYS are trademarks of Roche.

Research funding: BM and NT report research funding from Roche and the Alpha Phi Foundation related to highsensitivity troponin; DD reports research support from Roche, Siemens, and Ortho Clinical Diagnostics; RT reports research support from the Swiss National Science Foundation (Grant No. P300PB_167803), the Swiss Heart Foundation, the Swiss Society of Cardiology, the Cardiovascular Research Foundation Basel, the University of Basel and the University Hospital Basel.

Author contributions: All authors have accepted responsibility for the entire content of this manuscript and approved its submission.

Competing interests: $A Z$ is an employee of Roche Diagnostics International Ltd and holds stocks in F. Hoffmann-La Roche; AS is an employee of Roche Diagnostics $\mathrm{GmbH}$; DK is an employee of Roche Diagnostics International Ltd. BM has received an honorarium from AACC for a high-sensitivity troponin talk; RT reports speaker honoraria/consulting honoraria from Abbott, Amgen, Astra Zeneca, Roche, Siemens, 
Singulex and Thermo Scientific BRAHMS; NT has received an honorarium from AACC for a high-sensitivity troponin talk and served on a Roche advisory board related to biotin immunoassay interference. The sponsor was involved in study design, the collection and interpretation of the data, and writing of the manuscript.

Informed consent: Informed consent was obtained from all individuals included in this study.

Ethical approval: The original study received ethics approval from all relevant Institutional Review Boards, and was conducted in accordance with the principles of the Declaration of Helsinki and the International Conference on Harmonization guidelines for Good Clinical Practice.

\section{References}

1. Institute of Medicine. Dietary reference intakes for thiamin, riboflavin, niacin, vitamin $B 6$, folate, vitamin B12, pantothenic acid, biotin, and choline. A report of the Standing Committee on the Scientific Evaluation of Dietary Reference Intakes and its Panel on Folate, Other B Vitamins, and Choline. Washington, DC: National Academies Press; 1998.

2. Nerurkar LS, Namba M, Brashears G, Jacob AJ, Lee YJ, Sever JL. Rapid detection of herpes simplex virus in clinical specimens by use of a capture biotin-streptavidin enzyme-linked immunosorbent assay. J Clin Microbiol 1984;20:109-14.

3. Updyke TV, Nicolson GL. Immunoaffinity isolation of membrane antigens with biotinylated monoclonal antibodies and immobilized streptavidin matrices. J Immunol Methods 1984;73: 83-95.

4. Twerenbold R, Boeddinghaus J, Nestelberger T, Wildi K, Rubini Gimenez M, Badertscher P, et al. Clinical use of highsensitivity cardiac troponin in patients with suspected myocardial infarction. J Am Coll Cardiol 2017;70:996-1012.

5. Biener M, Mueller M, Vafaie M, Keller T, Blankenberg S, White HD, et al. Comparison of a 3-hour versus a 6-hour sampling-protocol using high-sensitivity cardiac troponin T for rule-out and rule-in of non-STEMI in an unselected emergency department population. Int J Cardiol 2013;167:1134-40.

6. Wildi K, Nelles B, Twerenbold R, Rubini Giménez M, Reichlin T, Singeisen $\mathrm{H}$, et al. Safety and efficacy of the $0 \mathrm{~h} / 3 \mathrm{~h}$ protocol for rapid rule out of myocardial infarction. Am Heart J 2016;181:16-25.

7. Pickering JW, Greenslade JH, Cullen L, Flaws D, Parsonage W, George P, et al. Validation of presentation and $3 \mathrm{~h}$ high-sensitivity troponin to rule-in and rule-out acute myocardial infarction. Heart 2016;102:1270-8.

8. Peacock WF, Baumann BM, Bruton D, Davis TE, Handy B, Jones CW, et al. Efficacy of high-sensitivity troponin $\mathrm{T}$ in identifying very-lowrisk patients with possible acute coronary syndrome. JAMA Cardiol 2018;3:104-11.

9. Fitzgerald RL, Hollander JE, Peacock WF, Limkakeng AT, Breitenbeck N, Blechschmidt K, et al. Analytical performance evaluation of the Elecsys $®$ Troponin T Gen 5 STAT assay. Clin Chim Acta 2019;495:522-8.
10. Peyro Saint Paul L, Debruyne D, Bernard D, Mock DM, Defer GL. Pharmacokinetics and pharmacodynamics of MD1003 (high-dose biotin) in the treatment of progressive multiple sclerosis. Expet Opin Drug Metabol Toxicol 2016;12:327-44.

11. Tourbah A, Lebrun-Frenay C, Edan G, Clanet M, Papeix C, Vukusic S, et al. MD1003 (high-dose biotin) for the treatment of progressive multiple sclerosis: a randomised, double-blind, placebocontrolled study. Mult Scler 2016;22:1719-31.

12. Sedel F, Papeix C, Bellanger A, Touitou V, Lebrun-Frenay C, Galanaud $D$, et al. High doses of biotin in chronic progressive multiple sclerosis: a pilot study. Mult Scler Relat Disord 2015;4:159-69.

13. Samarasinghe S, Meah F, Singh V, Basit A, Emanuele N, Emanuele MA, et al. Biotin interference with routine clinical immunoassays: understand the causes and mitigate the risks. Endocr Pract 2017;23: 989-98.

14. US Food and Drug Administration. The FDA warns that biotin may interfere with lab tests: FDA safety communication; November 28 2017. Available at: https://www.fda.gov/medicaldevices/safety/ alertsandnotices/ucm586505.htm [Accessed: 18 Jan 2019].

15. Li D, Radulescu A, Shrestha RT, Root M, Karger AB, Killeen AA, et al. Association of biotin ingestion with performance of hormone and nonhormone assays in healthy adults. JAMA 2017; 318:1150-60.

16. Piketty ML, Polak M, Flechtner I, Gonzales-Briceño L, Souberbielle JC. False biochemical diagnosis of hyperthyroidism in streptavidinbiotin-based immunoassays: the problem of biotin intake and related interferences. Clin Chem Lab Med 2017;55:780-8.

17. Kantor ED, Rehm CD, Du M, White E, Giovannucci EL. Trends in dietary supplement use among US adults from 1999-2012. JAMA 2016;316:1464-74.

18. Katzman BM, Lueke AJ, Donato LJ, Jaffe AS, Baumann NA. Prevalence of biotin supplement usage in outpatients and plasma biotin concentrations in patients presenting to the emergency department. Clin Biochem 2018;60:11-16.

19. Medical Laboratory Observer. Readers respond: a perspective about the rarity of biotin interference and mitigating risk; May 2018. Available at: https://www.mlo-online.com/home/article/ 13009487/readers-respond-a-perspective-about-the-rarity-ofbiotin-interference-and-mitigating-risk [Accessed 10 Feb 2020].

20. International Organization for Standardization. ISO 14971:2007. Medical devices - application of risk management to medical devices; March 2007. Available at: https://www.iso.org/ standard/38193.html [Accessed 18 Jan 2019].

21. Clinical and Laboratory Standards Institute. EP23-A $\mathrm{AM}^{\mathrm{TM}}$. Laboratory quality control based on risk management; approved guideline, 1st ed.; October 252011. Available at: https://clsi.org/ standards/products/method-evaluation/documents/ep23/ [Accessed 18 Jan 2019].

22. Wakabayashi K, Kodama H, Ogawa E, Sato Y, Motoyama K, Suzuki M. Serum biotin in Japanese children: enzyme-linked immunosorbent assay measurement. Pediatr Int 2016;58:872-6.

23. Grimsey P, Frey N, Bendig G, Zitzler J, Lorenz O, Kasapic D, et al. Population pharmacokinetics of exogenous biotin and the relationship between biotin serum levels and in vitro immunoassay interference. Int J Pharmacokinet 2017;2:247-56.

24. International Federation of Clinical Chemistry and Laboratory Medicine (IFCC). High sensitivity cardiac Troponin I and T Assay Analytical characteristics designated by manufacturer v122019. Available at: https://www.ifcc.org/media/478231/high- 
sensitivity-cardiac-troponin-i-and-t-assay-analyticalcharacteristics-designated-by-manufacturer-v122019.pdf [Accessed 14 July 2020].

25. Thygesen K, Alpert JS, Jaffe AS, Simoons ML, Chaitman BR, White HD, et al. Third universal definition of myocardial infarction. Eur Heart J 2012;33:2551-67.

26. Clinical and Laboratory Standards Institute. EP07. Interference testing in clinical chemistry, 3rd ed.; April 30, 2018. Available at: https://clsi.org/standards/products/method-evaluation/ documents/ep07/ [Accessed 18 Jan 2019].

27. Piketty ML, Prie D, Sedel F, Bernard D, Hercend C, Chanson P, et al. High-dose biotin therapy leading to false biochemical endocrine profiles: validation of a simple method to overcome biotin interference. Clin Chem Lab Med 2017;55:817-25.

28. Clevidence BA, Marshall MW, Canary JJ. Biotin levels in plasma and urine of healthy adults consuming physiological doses of biotin. Nutr Res 1988;8:1109-18.

29. LabCorp. Vitamin B7 test catalog menu; January 28, 2019. Available at: https://www.labcorp.com/test-menu/36691/ vitamin-bsub7-sub [Accessed 1 Feb 2019].

30. Trambas CM, Liu K, Louey W, Luu H, Wollbrandt K, Tan C, et al. Assessment of the risk of biotin interference affecting high sensitivity troponin T results in a Melbourne population (A254). In: Presented at the 71st AACC Annual Scientific Meeting and Clinical Lab Expo, Anaheim, CA, USA, August 4-8, 2019.

31. Katzman BM, Rosemark CL, Wockenfus AM, Block DR, Donato LJ, Karon BS, et al. Assessing the impact of biotin and simulating patient risk using the Elecsys Troponin T Gen 5 STAT assay [Abstract]. Clin Chem 2018;A-270:S90.

32. van der Linden N, Wildi K, Twerenbold R, Pickering JW, Than M, Cullen L, et al. Combining high-sensitivity cardiac troponin I and cardiac troponin $\mathrm{T}$ in the early diagnosis of acute myocardial infarction. Circulation 2018;138:989-99.

33. Lipinski MJ, Baker NC, Escárcega RO, Torguson R, Chen F, Aldous $\mathrm{SJ}$, et al. Comparison of conventional and high-sensitivity troponin in patients with chest pain: a collaborative meta-analysis. Am Heart J 2015;169:6-16.e6.

34. Amsterdam EA, Wenger NK, Brindis RG, Casey DE, Jr., Ganiats TG, Holmes DR, Jr., et al. AHA/ACC guideline for the management of patients with non-ST-elevation acute coronary syndromes: executive summary: a report of the American College of Cardiology/American Heart Association Task Force on Practice Guidelines. Circulation 2014;130:2354-94.
35. Roffi M, Patrono C, Collet JP, Mueller C, Valgimigli M, Andreotti F, et al. ESC Guidelines for the management of acute coronary syndromes in patients presenting without persistent ST-segment elevation: Task Force for the Management of Acute Coronary Syndromes in Patients Presenting without Persistent ST-Segment Elevation of the European Society of Cardiology (ESC). Eur Heart J 2015;37:267-315.

36. Clase CM, Ki V, Holden RM. Water-soluble vitamins in people with low glomerular filtration rate or on dialysis: a review. Semin Dial 2013;26:546-67.

37. deFilippi CR, Herzog CA. Interpreting cardiac biomarkers in the setting of chronic kidney disease. Clin Chem 2017;63:59-65.

38. Tate J, Ward G. Interferences in immunoassay. Clin Biochem Rev 2004;25:105-20.

39. Ungerer JP, Marquart L, O'Rourke PK, Wilgen U, Pretorius CJ. Concordance, variance, and outliers in 4 contemporary cardiac troponin assays: implications for harmonization. Clin Chem 2012;58:274-83.

40. Bais R. The effect of sample hemolysis on cardiac troponin I and T assays. Clin Chem 2010;56:1357-9.

41. Saenger AK, Jaffe AS, Body R, Collinson PO, Kavsak PA, Lam CSP, et al. Cardiac troponin and natriuretic peptide analytical interferences from hemolysis and biotin: educational aids from the IFCC Committee on Cardiac Biomarkers (IFCC C-CB). Clin Chem Lab Med 2019;57:633-40.

42. Yagi S, Nishizawa M, Ando I, Oguma S, Sato E, Imai Y, Fujiwara M. A simple and rapid ultra-high-performance liquid chromatography-tandem mass spectrometry method to determine plasma biotin in hemodialysis patients. Biomed Chromatogr 2016;30:1285-90.

43. Trambas C, Lu Z, Yen T, Sikaris K. Characterization of the scope and magnitude of biotin interference in susceptible Roche Elecsys competitive and sandwich immunoassays. Ann Clin Biochem 2018;55:205-15.

44. Schrapp A, Fraissinet F, Hervouet C, Girot H, Brunel V. Biotin and high-sensitivity cardiac troponin T assay. Biochem Med (Zagreb) 2018;28:030901.

Supplementary Material: The online version of this article offers supplementary material (https://doi.org/10.1515/cclm-20190962). 